\title{
Syrian Hamster
}

National Cancer Institute

\section{Source}

National Cancer Institute. Syrian Hamster. NCI Thesaurus. Code C77095.

All Syrian hamsters in captivity are derived from a mother and eight pups that were captured in the wild in Aleppo, Syria by Dr. Israel Aharoni in 1930. Syrian Hamsters exhibit multiple coat colors, gold being the most common, and have a life span of about two to three years. Syrian hamsters are extremely territorial and are prone to attacking other hamsters so cannot be housed together under most circumstances. Females come into estrus every four days and embryo gestation is 16-18 days long. Syrian hamsters may exhibit diarrhea, neoplasms, amyloidosis, polycystic disease, and pregnancy-associated toxemia. 